\title{
FUNCTIONAL ASPECTS OF THE DIFFERENTIAL DIAGNOSIS OF RENAL DISEASE
}

\author{
JaN Brod, M.D., D.Sc. \\ Director, Institute jor Cardiovascular Research, Prague 4, Czechoslovakia
}

IF we read through both the basic papers which William Bright wrote some 136 and 127 years ago, and which laid the foundations of clinical nephrology, we can recognize in the detailed clinical description the nephrotic syndrome, the effects of severe hypertension and the signs of chronic renal or cardiac insufficiency. These are the endstages which follow almost all types of chronic renal disease, and these late phenomena cannot be used to differentiate between the various morphological entities which the pathologists later constructed from the original tissue of 'Bright's disease '. Such a differentiation was, of course, to no purpose at the period when therapeutic medicine knew little else than venesection, calomel, diaphoretics, suction-cups and a few other drugs which Bright prescribed with both enthusiasm and conviction for his patients. Even in the century following Bright we had little else in our therapeutic armamentarium than a lowprotein, low-salt diet and fluid restriction, so that, again, the differential diagnosis of renal disease was to little avail.

The situation in therapy today is quite different, and attempts at differential diagnosis have thereby taken on considerable practical importance. Since morphology of the kidney itself has been the classical criterion of diagnosis, kidney biopsy can be of great assistance, particularly when combined with histochemistry and electron microscopy of the biopsy material. These latter techniques have taught us a great deal of the early stages of kidney disease, since such cases do not come to the postmortem table. It must be stressed, however, that biopsy is not without risk, that it requires the services of a pathologist experienced in interpreting such material, that even in the best of hands about one-quarter of all biopsies ends up with no kidney tissue in the needle, that the biopsy piece may contain so few glomeruli that any interpretation at all is risky, and that one has no guarantee at all that the region of kidney punctured by the needle actually contains the disease

Lecture given at the London Hospital on June 20, 1962 , and at Bristol University on July 3, 1962 . process, which might be present only in other portions of the organ. In chronic pyelonephritis, for example, we can find quite normal areas of kidney in close approximation to areas severely altered by the chronic process.

However, morphological criteria are but one consequence of the disease-process-the other consequence consisting of the renal functional changes, which are no less specific than the details of micro-morphology. Our own work, and that of others, has led us to the conclusion that a study of renal function can give us a great deal of information not only concerning the degree of the disease process-hitherto its main application-but also as to the nature of the disease process, with a high degree of reliability. I hope that the material I shall present you, summarising some 25 years of observations on 3,685 patients will transmit this conviction to you as well.

\section{Methods}

The methods used by us in these studies are by no means highly specialized ones-they are within the reach of any local hospital, and in Czechoslovakia they have been introduced into the routine investigational procedure of most medical wards. In addition to history and physical findings, they include: (I) qualitative and quantitative analysis of urine in terms of the content of protein and formed elements in the Addis sediment; (2) an approximation to glomerular filtration rate by means of the endogenous creatinine clearance in one 24-hour urine sample or in several 3 - to 4-hour specimens over the course of a single day; (3) measurement of the concentrating ability, which is a very sensitive indicator of tubular function; (4) in selected cases investigation of diluting ability; (5) in cases where asymmetry of the disease-process is suspected, investigation of creatinine concentration or clearance measurements with urine obtained from each ureter separately by catheterization; (6) where indicated, urography, pyelography, aortography or tomography with retroperitoneal air insufflation; (7) if bacterial infection is suspected, the urine is cultured, and if the culture is positive then quantitative estimation of bacterial contamination of the urine is carried out. If there are more than 10,000 organisms per $\mathrm{ml}$. of urine, bacterial infection is highly suspect, and if this count is greater than 100,000 infection is certain.

Functional Classification of Renal Diseases

The simplest method of functional classification 
of renal disease is according to the degree to which glomerular and tubular function is altered viz:

(I) There are disease-states which primarily involve glomerular filtration, leaving tubular function intact.

(2) There are others in which glomerular and tubular function are altered in a more or less parallel fashion.

(3) There are further states in which tubular malfunction is the only demonstrable defect for long in the course of the disease, glomerular alteration being a late development (Table I).

\section{TABLE I} Functional Classification of Chronic

I. Glomerular Function Restricted more than Tubular Function

A. On Hamodynamic Basis:

I. Orthostatic proteinuria

2. Emotional proteinuria

3. Exertional proteinuria

4. Heart failure

5. Essential hypertension (early)

B. On Organic Basis:

(a) Without grave changes of basal membrane:

Vascular nephrosclerosis

(b) With grave changes of basal membrane:

1. Diabetic glomerulosclerosis

2. Amyloidosis

3. Nephropathia gravidarum

II. Parallel Reduction of Glomerular and Tubular Function: Glomerulonephritis

III. Tubular Function Restricted MORE THAN Glomerular Function:

I. Chronic pyelonephritis

2. Polycystic kidney disease

In individual sub-groups it is of assistance to determine the quality of the glomerular abnormality, the presence of the nephrotic syndrome, hypertension, infection, etc.

\section{Disease-states with Primary Involvement of the Glomerular Apparatus}

Glomerular filtration can be decreased by lesions which restrict the filtration area with infiltration or scar formation, despite a lack of tubular involvement, but also by any state causing vasoconstriction in the kidney. In the first group we find diabetic glomerulosclerosis, renal amyloidosis, toxæmia of pregnancy and primary nephrosclerosis arising on the basis of hypertension of long duration. In the second group we find states in which there is a generalized hæmodynamic reaction to an imbalance between the tissue requirement of oxygen and the ability of the circulatory apparatus to deliver it to the tissues, resulting in vasodilation in muscles and adrenergic vasoconstriction in the splanchnic bed, the kidneys, and skin. Renal vasoconstriction may气 result in a decrease in glomerular filtration. $\operatorname{Such}_{\mathbb{\infty}}$ a decrease of glomerular filtration in an otherwise $\stackrel{\varrho}{c}$ intact nephron, regardless of how it comes about, has, among others, two consequences of interest: (I) The decreased filtered load of osmotic materiato to the individual nephron has the opposite effecto on final osmolarity of the urine to that of the raised osmotic load in osmotic diuresis. Here, $\mathbb{\complement}$ as we know, urine osmolarity decreases asymptotically in the direction of plasma osmolarity. With a decrease in filtered osmotic load urine osmolarity. is increased to high values, even in the absence of ADH (Shannon, I942; de Wardener and del Greco, 1956). (2) When glomerular filtrate is low: and the plasma coursing through the glomerulus is in contact with this structure for a longer-than-i normal period, there is a greater-than-normali diffusion of protein into the glomerular filtrateco (Goværts and Lambert, 1953). At least in some $\frac{\vec{\sim}}{\sim}$ nephrons this diffusion may lead to amounts ${ }^{-}$ of protein in the lumen which cannot be re-을 absorbed in entirety by the tubular cells. The unreabsorbed remnant appears then in the urines along with occasional hyaline casts which are thes gel-form of this protein, but also with occasional tubular cells and granular casts due to saturationge of these cells with protein transport and subse- $\omega$ quent disintegration (Addis, 1942).

This is the mechanism of proteinuria which occurs with severe muscular exercise, and duringo orthostasis in some individuals with circulatoryo dysregulation in the erect posture (orthostatic proteinuria), with so-called 'negative emotionat states' such as fear, anxiety, anticipation-these 3 latter situations being hæmodynamically com parable to preparation for muscular activity (Brod, Fencl, Hejl and Jirka, 1959), and ine congestive failure. In the first three states. mentioned above, there is no protein in the morn- -3 ing urine, which immediately suggests that there is no organic disease in the kidneys themselves. $\frac{\rho}{3}$ Greater confusion can be caused by the proteinuria of congestive failure, which lasts as long as failure is present: if there is nocturia, the diurnal curve of glomerular filtration shows a rise to normal at= night, which is of diagnostic significance (Fig. I) (Brod and Fejfar, 1950). In severe cases, where glomerular filtration is depressed over the entires 24 hours and the protein and cellular content of $\sigma_{\sigma}^{\omega}$ the urine is somewhat higher, high urine specific gravity, which shows a normal nephron popula $\frac{O}{D}$ tion even with a glomerular filtration rate as low as? 50 to $30 \mathrm{ml} . / \mathrm{min}$., can exclude organic renato disease. In these cases, blockage of the adrenergic mechanism by means of dibenamine will bes followed by a rise in renal plasma flow and $\overrightarrow{\mathbb{Q}}$ 


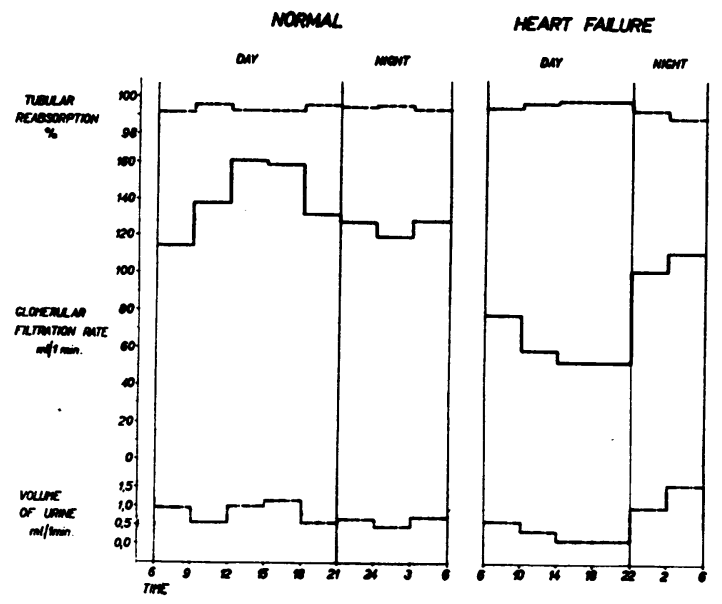

Fig. 1.-Diurnal rhythm in the rate of glomerular filtration (GFR), tubular reabsorption of water (R) and urine flow (V) in a normal subject and in a patient with heart failure. $\mathrm{R}$ is given as $\%$ of GFR $\left(\frac{\mathrm{GFR}-\mathrm{V}}{\mathrm{GFR}} \times 100\right)$ and varies normally between narrow limits $(98.3$ to $99.7 \%$ ). Note that the nocturia in the cardiac patient is due in the first place to an increase of GFR from subnormal values in day-time to low-normal values at night.

glomerular filtration (Brod, Fejfar and Fejfarová, 1954).

A similar situation might be encountered in the initial stages of essential hypertension, where the kidneys are morphologically intact and where a decreased glomerular filtration rate is due to vasoconstriction. Glomerular filtration rises when blood pressure is normalised with rauwolfia (Brod and Fencl, r955), during sleep (Brod and Fencl, 1958), with sedatives (Ratněr, 1959) and pyrogens (Bradley, Chasis, Goldring and Smith, 1945). Suspicion of primary renal disease can remain in this case only if we find proteinuria. In our experience, however, the latter is not frequent or significant and the urinary sediment with proteinuria does not differ from that found in cases of orthostatic proteinuria.

Proteinuria in essential hypertension becomes a more fixed part of the disease-picture when the high blood pressure has lasted some time and has led to arteriolosclerotic changes in the renal vessels with the start of slow, progressive vascular nephrosclerosis involving part of the glomerular vascular bed. In this latter situation the diurnal variation in glomerular filtration rate is decreased or disappears entirely. Even in such cases the degree of proteinuria usually does not exceed $\mathrm{I}$ g./ $24 \mathrm{hr}$. with uncomplicated vascular nephrosclerosis. The Addis count shows only a small

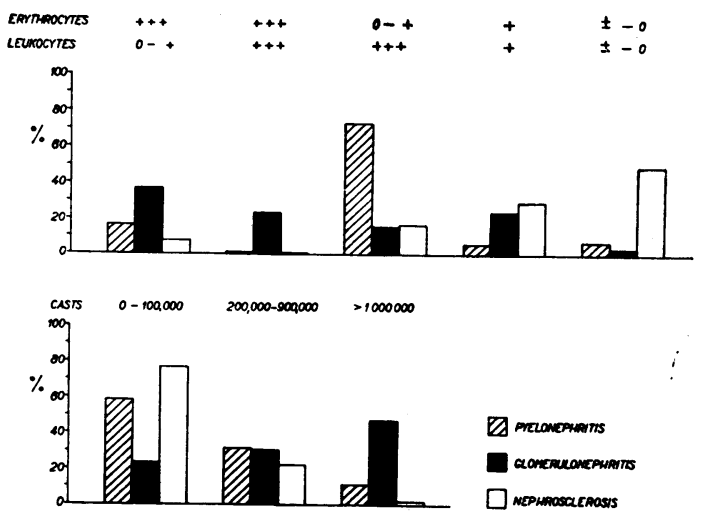

FIG. 2.-Frequency of the various types of Addis count in chronic pyelonephritis, chronic glomerulonephritis and vascular nephrosclerosis.

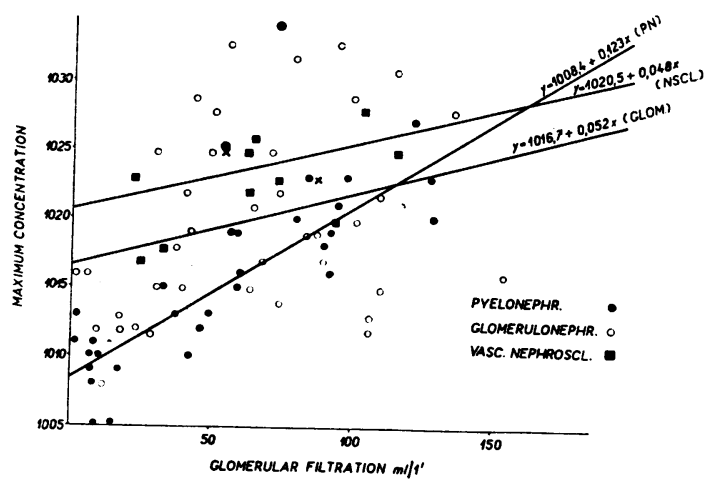

FIG. 3.-Correlation of glomerular filtration and maximum concentrating ability in patients with vascular nephrosclerosis (NSCL), chronic glomerulo nephritis (GLOM) and chronic pyelonephritis (PN). The diagnosis in all patients has been proved morphologically (biopsy or autopsy). At all stages of the restriction of GFR patients with chronic pyelonephritis concentrate less and patients with vascular nephrosclerosis concentrate better than patients with chronic glomerulonephritis.

rise in formed elements and casts, with values seldom exceeding 200,000 to 300,000 (Fig. 2). With destruction of glomeruli, entire nephrons are then put out of action, thus increasing the osmotic load on the remaining nephrons. An osmotic diuresis results which limits the concentrating ability of the kidney, but the latter impairment is mild in comparison with the degree of limitation of glomerular filtration, as can be seen in Fig 3 .

Renal artery stenosis, which is present in a portion of hypertensive patients, regardless of whether it is the causative agent of the hypertension or merely a complicating factor, does not produce a different functional picture from that 


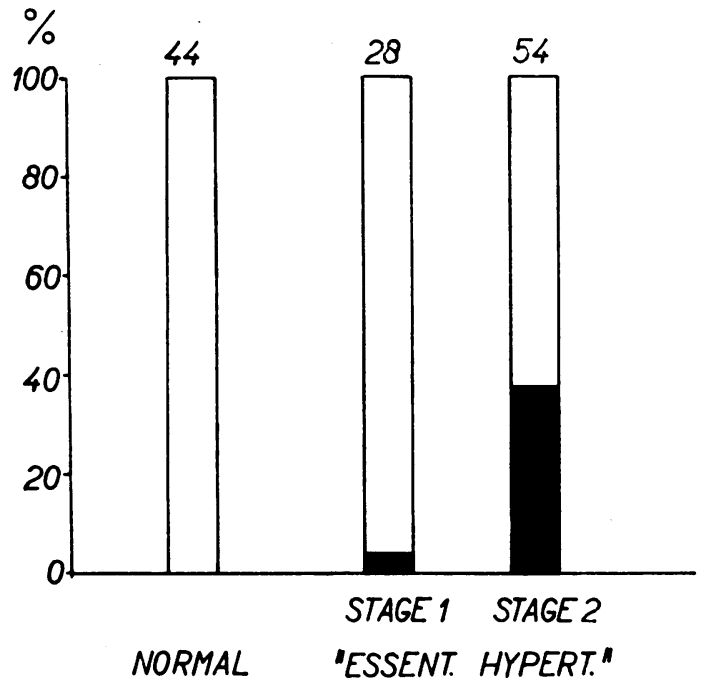

REN ART. STENOSIS

FIG. 4.- Incidence of renal artery stenosis in normotensive subjects and in patients with essential hypertension divided according to the absence or presence of clinical signs of organic cardiovascular changes into stages I and II (Hejl, Prát and Dejdar, 1962).

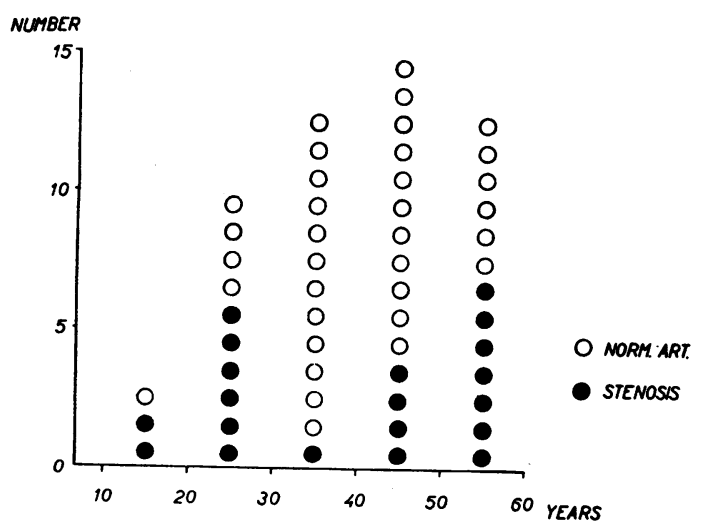

FIG. 5.-Prevalence of renal artery stenosis according to age (Hejl, Prát and Dejdar, 1962).

just described. As can be seen in Fig. 4 (Hejl, Prát and Dejdar, 1962) this finding is rare $(3 \%)$ in the early phases of hypertension, whereas in patients with organic complications renal artery stenosis was found in $38.5 \%$ of cases, and in juvenile hypertensives in this stage of the disease actually in $46 \%$. This would suggest that renal artery stenosis is a secondary phenomenon due $\$_{0}$ acceleration of the atherosclerotic process in hypertension. However, the age distribution of patients with renal artery stenosis (Fig. 5), with a clegir double-peaked curve, allows the possibility thgt stenosis in young patients can be a separate disease entity and be associated with the later develo ment of hypertension. Our present research programme with aortographic investigation of all hypertensives found in a large, unselected popula tion, should give the answer to this question. The preliminary data do show that suspicion of stenosis is aroused in cases of severe hypertensien with signs of organic cardiovascular involvement, particularly if there is apparent asymmetry of the kidneys in the plain abdominal X-ray.

Small changes in the basement membrane of the glomerular capillaries, the slight degree of escape of protein into the glomerular filtrate and finat urine, the insignificant changes in the urinapy sediment and the lack of signs of protein depletion differentiate the renal correlate of hypertensiog (primary vascular nephrosclerosis) from the other three disease processes which involve the filtration area of the glomerulus: diabetic glomerulosclgre sis, renal amyloidosis and nephropathy of piegs nancy. In these diseases, there is a deposident of mucoproteins and mucopolysaccharides, mañ festations of a generalized metabolic disturbance, in the basement membrane of the glomerular capillaries. In amyloidosis this infiltration can also be in the basement membrane of the tubules. This deposition in the glomerular-capillary wals leads to an enormous rise in glomerular pet meability to protein, with intense proteinuria saturation of the tubular cells with reabsorbed protein and the appearance of such packed cells as well as of their product-granular casts in the urinary deposit, and finally the appearance of the nephrotic syndrome. There is a progressize decrease in the glomerular filtration area, wi角 final disappearance of filtration.

Diabetic glomerulosclerosis, or Kimmelstie Wilson disease, is found in some $22.9 \%$ (How and Smetana, 1942) to $63.7 \%$ (Laipply, Eitze्रु and Dutra, 1944) of diabetics, depending of whether one uses as the histological criterion of the diagnosis the presence of characteristic hyalinf balls or diffuse thickening of the basement membrane, the latter being an earlier stage of tee lesion (Fig. 6a, b).

Diabetic glomerulosclerosis is one of the most difficult of clinical diagnoses, since we onty recognize it pre-mortem in $6.3 \%$ of diabetice The causes of the different percentages noted bf the pathologist and the clinician are two 

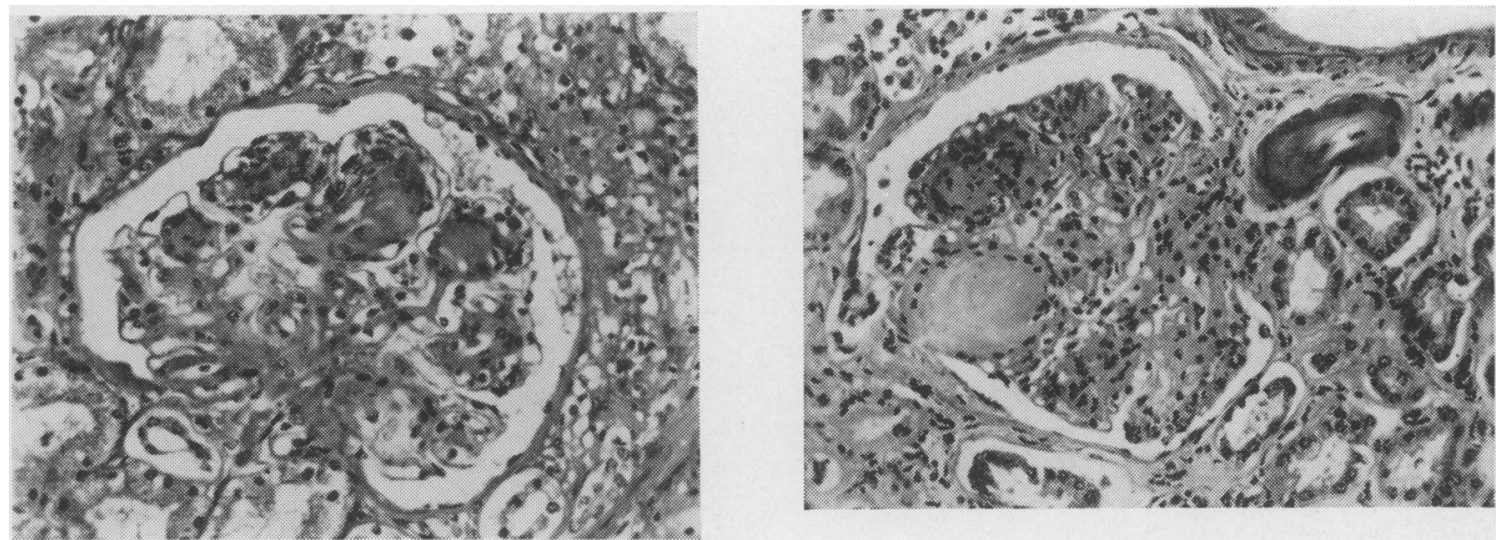

Fig. 6.-Microscopical picture of diabetic glomerulosclerosis. (a) Early-with predominant thickening of the capillary walls; (b) late - with typical formation of nodules (courtesy of Dr. Rossmann).

number: in some of our diabetics we make the wrong diagnosis of glomerulosclerosis from proteinuria and odema which are actually due to congestive failure. On the other hand, in the initial stages the presence of morphological changes need not be accompanied by pathological changes in the urine (Brun, Gormsen, Hilden, Iversen and Raaschou, 1953). We are therefore faced with the prospect that diagnosis at an early stage, which by correction of the metabolic disturbance might perhaps still be amenable to therapy, will be only possible by repeated biopsy during the course of diabetes, and will probably require electron microscopy to detect changes which are difficult to see under ordinary microscopy. By the time the disease presents itself clinically-which is rare in a diabetic of less than ten years duration-there is usually a rapid progression to uræmic death or cardiac failure or both which, according to our own experience, supervene within four to five years of the first clinical recognition of this disease.

The functional diagnosis (Table 2) is based upon: (I) Proteinuria in $100 \%$ of cases, with more than $10 \mathrm{~g} . / 24 \mathrm{hr}$. in $56.4 \%$, and numerous tubular cells, counted along with the leucocytes in the Addis count, and casts. Due to the defect in fat metabolism also present, the casts and epithelial

TABLE 2

The Lfading Diagnostic Features of Diabetic Glomerulosclerosis and Renal Amyloidosis. Chronic PYELONEPHRITIS HAS BEEN PRESENTED FOR COMPARISON

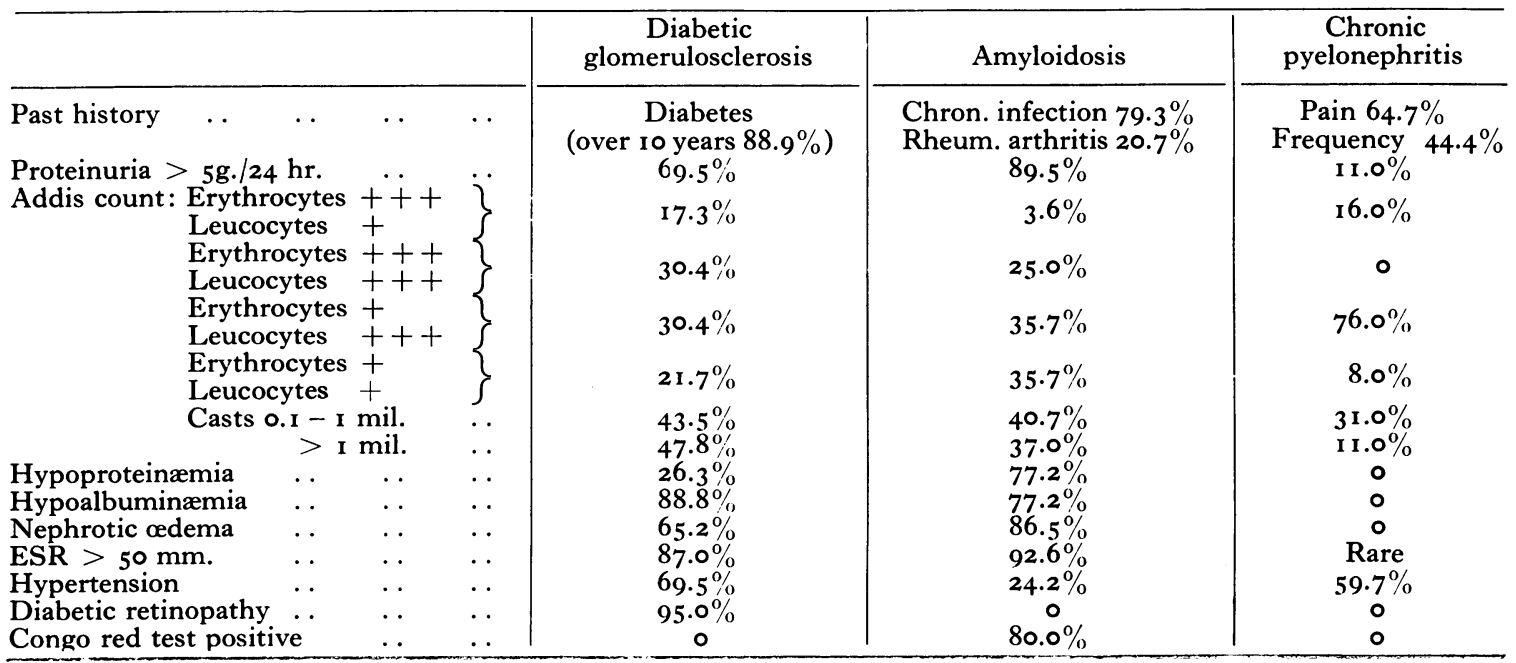




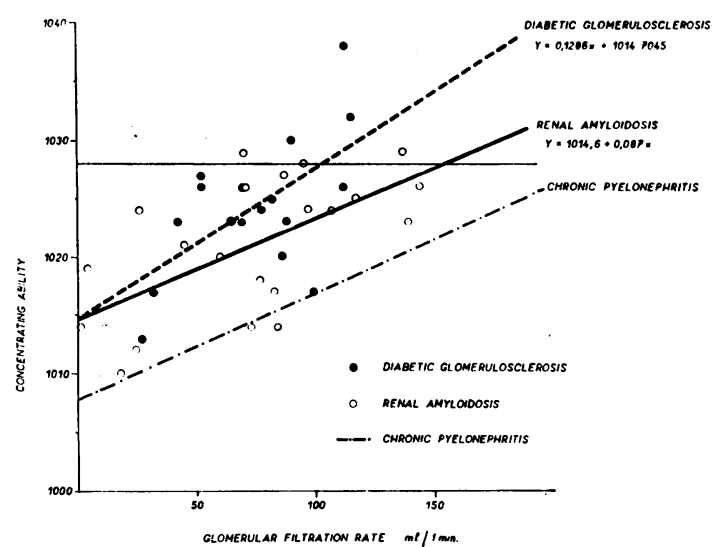

FIG. 7.-Correlation of glomerular filtration and maximum concentrating ability in patients with diabetic glomerulosclerosis, renal amyloidosis and chronic pyelonephritis. The diagnosis in all patients has been proved histologically. There is no great difference in the relationship in the first two diseases. The regression line for chronic pyelonephritis is far below those for the other two diseases.

cells are filled with refractile droplets of fat. 'Leucocytes' in the Addis count usually exceed 50 million $/ 24 \mathrm{hr}$. only when there is urinary tract infection also present. Erythrocytes are not prominently represented in the sediment. The severe proteinuria results in the nephrotic syndrome, present in $65.2 \%$ of clinically diagnosed cases, and present in all patients with a daily loss of protein greater than $5 \mathrm{~g}$. Progressive decrease in glomerular filtration rate, also contributed to by congestive failure and atherosclerotic closure of the smaller renal vessels, is in contradistinction to the normal concentrating ability. The latter may decrease late in the course of the disease due to osmotic diuresis from reduction of the nephron population, just as in primary vascular nephrosclerosis (Fig. 7). In three patients in whom the exceptional finding of hyposthenuria was present, there was also urinary tract infection.

Aside from the kidneys, there are specific diabetic lesions in the retinal vessels, which were present in $95 \%$ of our cases. The reverse is not true, however. Iversen and Ohlsen (I95I) reported that only seven of 16 diabetics with retinopathy showed simultaneous signs of a renal lesion.

We found hypertension less frequently than would be expected from the earlier reports. Normal pressures were found in two of 23 patients and five showed the 'windkessel' type of hypertension. Definite diastolic hypertension was present in $69.5 \%$ of cases, but there was no correlation between the degree of the latter and the degree of

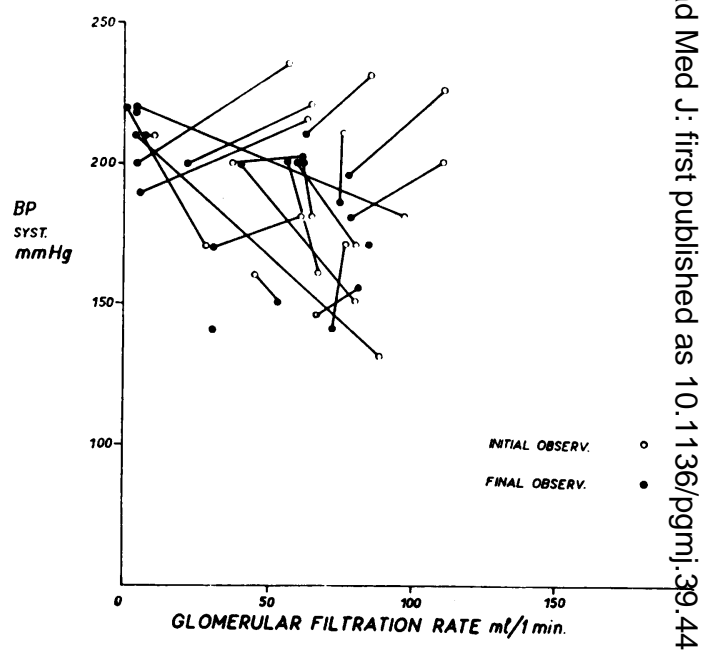

FIG. 8.-Correlation between systolic blood pressure and the rate of glomerular filtration in patients with diabetic glomerulosclerosis. Although there is a slight tendency to higher pressures in patiegts with severely restricted GFR, the correlation is very low. The same is true for diastolic pressure.

$\frac{\mathrm{N}}{\mathrm{O}}$

alteration in the rate of glomerular filtrgifign (Fig. 8).

It is clear, then, that the diagnostic sig $\& \mathrm{f}$ diabetic glomerulosclerosis are diabetes of To duration and retinopathy, without which the rearl lesion does not appear, the finding of marked proteinuria with only insignificant hæmaturia, $b \$$ with many fat-containing epithelial cells a granular casts, marked decrease in glomeruar filtration with relatively little change in co $\overline{7}-$ centrating ability, and the presence of the nephretic syndrome. As we shall see, these criteria quite the reverse of what is found in chrowic pyelonephritis, which is another frequent comp\$ication in diabetes and may, of course, atso complicate diabetic glomerulosclerosis. Signs of pathology in the basement membrane of the glomerular capillaries (proteinuria, nephrotic sy?drome) differentiate diabetic glomerulosclerosis from hypertensive disease per se and from vascuar nephrosclerosis, both of which may complicate the course of diabetes mellitus (Table 3 ).

On the other hand, it is very difficult to d ferentiate on functional grounds renal amyloidosos from diabetic glomerulosclerosis, if the former isa complication of a purulent or wasting disease which has also occurred in the course of diabetes: the absence of retinopathy and the presence of $?$ a normal blood pressure are of assistance.

The causes of amyloidosis in our series of cases are shown in Table 4. The first clinical signs of amyloidosis appeared from three montbs 
TABLE 3

Differential Diagnosis of Diabetic GlomeruloSClerosis, Renal AMyloidosis and Vascular NephroSCLEROSIS

\begin{tabular}{|c|c|c|c|}
\hline & $\begin{array}{l}\text { Diabetic } \\
\text { glomerulo- } \\
\text { sclerosis }\end{array}$ & $\begin{array}{c}\text { Amyloi- } \\
\text { dosis }\end{array}$ & $\begin{array}{l}\text { Vascular } \\
\text { nephro- } \\
\text { sclerosis }\end{array}$ \\
\hline 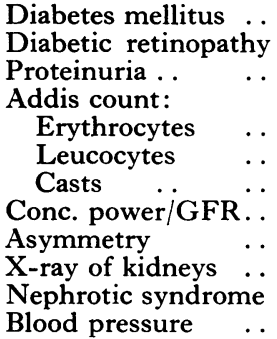 & $\begin{array}{c}>\text { ro yrs. } \\
+++ \\
+++ \\
+ \\
++ \\
+++ \\
\uparrow \\
0 \\
0 \\
++ \\
\uparrow\end{array}$ & $\begin{array}{c}- \\
+\overline{+}+ \\
+ \\
++ \\
+++ \\
\uparrow \\
0 \\
0 \\
++ \\
-\end{array}$ & $\begin{array}{c}- \\
0- \pm \\
0- \pm \\
0- \pm \\
0- \pm \\
\uparrow \\
0 \\
\frac{0}{\uparrow}\end{array}$ \\
\hline
\end{tabular}

TABLE 4

Causes of Amyloidosis and Signs of Simultaneous Involvement of Other Organs Among the Patients OF THE INSTITUTE for CaRdiovascular Research

\begin{tabular}{ccccc}
\hline CAUSES OF AMYLOIDOSIS: & & & & \\
Tuberculosis of bones & $\ldots$ & $\ldots$ & 8 & $(27.6 \%)$ \\
Tuberculosis of lungs & $\ldots$ & $\ldots$ & 6 & $(20.7 \%)$ \\
Bronchiectasis $\ldots$ & $\ldots$ & $\ldots$ & 4 & $(13.8 \%)$ \\
Rheumatoid arthritis & $\ldots$ & $\ldots$ & 6 & $(20.7 \%)$ \\
Chronic osteomyelitis & $\ldots$ & $\ldots$ & 3 & $(10.3 \%)$ \\
Ulcerative colitis.. & $\ldots$ & $\ldots$ & I & $(3.45 \%)$ \\
Lymphogranulomatosis & $\ldots$ & $\ldots$ & I & $(3.45 \%)$ \\
Total & $\ldots$ & $\ldots$ & 29 & $(100.0 \%)$
\end{tabular}

Simultaneous Clinical Involvement of Other ORGANS:

\begin{tabular}{lllllll} 
Liver & $\ldots$ & $\ldots$ & $\ldots$ & $\ldots$ & 9 & $(31.0 \%)$ \\
G.I. tract & $\ldots$ & $\ldots$ & $\ldots$ & $\ldots$ & 4 & $(13.8 \%)$ \\
Spleen $\ldots$ & $\ldots$ & $\ldots$ & $\ldots$ & $\ldots$ & 4 & $(13.8 \%)$ \\
\hline
\end{tabular}

to 32 years after the start of the initial pathology, with an average of II.3 years, and there was no clustering of cases in this wide range of time. There were signs of extra-renal amyloidosis in $34.4 \%$ and the Bennhold (Congo Red) test was positive in $80 \%$, and at the lower margin of significance in $12 \%$.

Proteinuria (Table 2 ) is usually massive from the very start: $86.3 \%$ excreted more than $5 \mathrm{~g}$. in 24 hr. and showed the presence of the nephrotic syndrome. As in diabetic glomerulosclerosis, there are many epithelial cells in the 'leucocyte' fraction of the Addis count and many casts, with only mild red-cell excretion.

Fig. 7 shows the regression curve of the rate of glomerular filtration and concentrating ability in our cases, and this was not markedly different from that found in nephrosclerosis and glomerulosclerosis. The somewhat greater scatter of values in some cases with markedly decreased concentrating ability, with only moderate decrease in glomerular filtration, is probably due to the presence of amyloid in the basement membrane of the tubules and collecting ducts.

Hypertension proved to be rare despite the marked degree of renal pathology (Fig. 9). Only five patients had a raised pressure, and three of these had very low rates of glomerular filtration. It is difficult to say whether the absence of hypertension is due to the presence of the provocative disease or focus or to some other cause.

The lack of hypertension can to some degree be used in the differential diagnosis of renal diseases with massive proteinuria and the nephrotic syndrome, and in the case of glomerulonephritis further assistance is given by the history, the predominance of erythrocytes in the Addis count and the presence of erythrocyte-and bloodcasts (Table 3). In the case of disseminated lupus erythematosus there are in addition signs of systemic involvement. When the nephrotic syndrome is present along with thrombophlebitis of the lower extremities or constrictive pericarditis, or the appropriate histories thereof, one must also consider the rare possibility of thrombosis of the renal vein.

The importance of early diagnosis of rena amyloidosis can be seen from evidence that radical treatment of the evocative pathologica $F$ process leading to amyloidosis in the early stages of the latter can occasionally prevent the further progress of renal degeneration.

The last of the diseases in this grouptoxamia of pregnancy-also involves a deposition of mucopolysaccharides in the basement membrane of the glomerular capillaries. This again leads to proteinuria and an increase in tubular cells present in the 'leucocyte' fraction of the Addis count, along with hyaline and granular casts and a moderate decrease in glomerular filtration rate. For the same reasons as in renal amyloidosis, tubular concentrating ability remains fairly well preserved in the face of restriction of the rate of glomerular filtration. Diagnostic difficulties arise in differentiating between nephropathia gravidarum and glomerulonephritis or the renal affection in hypertension (Table 5). As opposed to the hypertensive kidney, nephropathia gravidarum is associated with a greater degree of proteinuria, more elements in the urinary sediment, a lower filtration fraction, œdema and hypoproteinæmia. Glomerulonephritis, on the other hand, is differentiated by many more red cells and erythrocytic casts in the urinary sediment, by a far greater restriction of the concentrating ability, and by the history, if it is known that the renal disease started before 


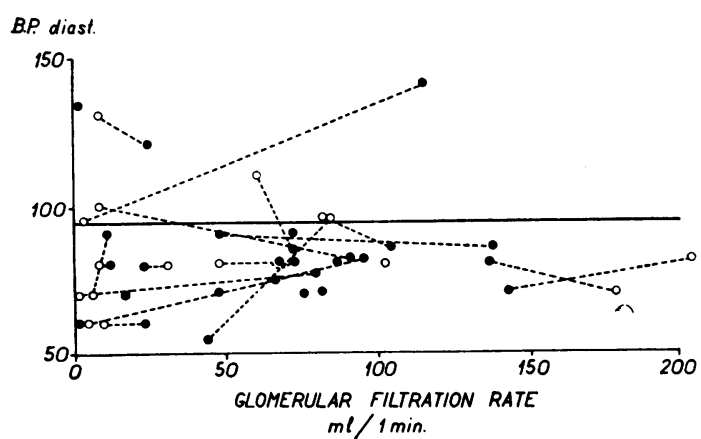

Fig. 9.-Correlation between diastolic pressure and the rate of glomerular filtration in patients with renal amyloidosis. It may be noted that with one exception the only registered elevations of blood pressure were found in patients with a severely restricted GFR.

TABLE 5

Differential Diagnosis of Toxamia of Pregnancy

\begin{tabular}{|c|c|c|c|}
\hline & $\mid \begin{array}{c}\text { Toxæmia } \\
\text { of } \\
\text { pregnancy }\end{array}$ & $\begin{array}{l}\text { Essential } \\
\text { hyper- } \\
\text { tension }\end{array}$ & $\begin{array}{c}\text { Glomerulo- } \\
\text { nephritis }\end{array}$ \\
\hline 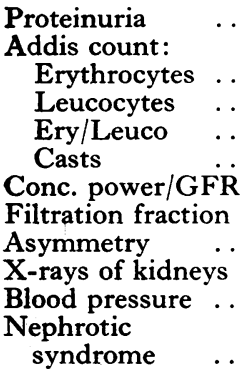 & $\begin{array}{l}++ \\
\pm \\
++ \\
\downarrow \\
++ \\
\uparrow \\
\frac{\downarrow}{-} \\
\uparrow \\
+\end{array}$ & $\begin{array}{c}0- \pm \\
0- \pm \\
0- \pm \\
- \\
\frac{\uparrow}{\uparrow} \\
\frac{1}{-} \\
\uparrow\end{array}$ & $\begin{array}{c}++ \\
+++ \\
++ \\
\uparrow \\
++ \\
= \\
\downarrow \\
- \\
0-\uparrow \\
+\end{array}$ \\
\hline
\end{tabular}

pregnancy. Pyelonephritis is a common renal complication of pregnancy, but the functional diagnosis is quite clear in terms of differentiation from nephropathia gravidarum.

\section{Renal Disease, Involving Glomerular and Tubular Function in Parallel}

Our second group of renal diseases is represented in the first instance by glomerulonephritis. The name itself tells us that the disease process involves the glomeruli, and experimental work over the past I 5 years has shown that immunotoxic reactions, thought to lie at the basis of this disease, can produce a similar picture in animals and that the antigen-antibody reaction occurs in the basement membrane of the glomerular capillaries. However, the work of Schwentker and Comploier (1939) and the more recent observation of Antoine (196I) have shown that other renal

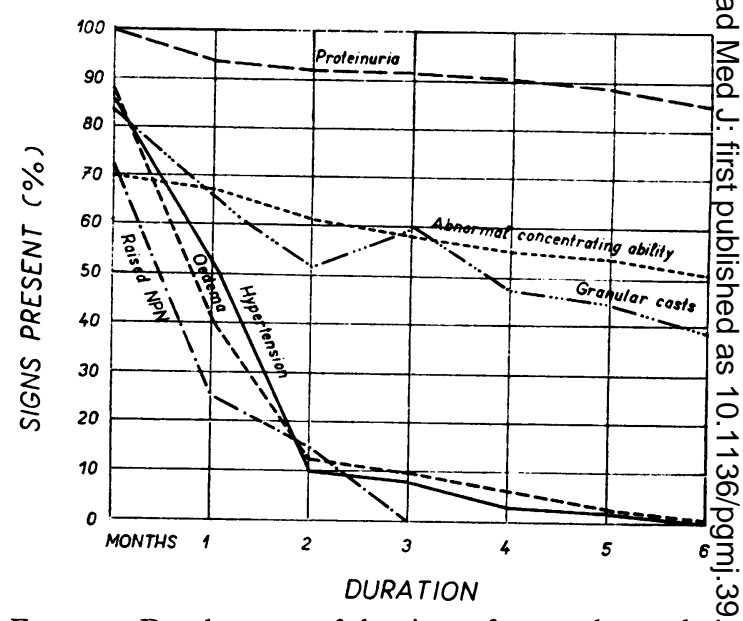

FIG. 10.-Development of the signs of acute glomerulo-i nephritis in the course of the first six months. Ordinate indicates the percentage incidence of the individual sign. Note the more or less parallel retreat of œdema, hypertension and raised NPN (an indirect indicator of glomerular obstruction)을 and the persistence of proteinuria, granular casts and reduced concentrating ability (Brod, 1949).

structures, in particular the tubules, can also seræe $\vec{\varnothing}$ as the antigen-container for this immunologieal reaction. The decrease in concentrating abilit. early in the course of acute glomerulonephritis could be attributed to the osmotic effect of a decreased nephron population. Against this argument is the fact that reduced concentrating $\stackrel{\odot}{\mathscr{Q}}$ ability remains for months after signs of the acute $\overrightarrow{\vec{P}}$ stage of the disease, such as a low glomerular $\frac{0}{3}$ filtration, have been completely normalized $\frac{\partial}{2}$ (Fig. 10).

Despite a large amount of experimental data, the pathological basis of glomerulonephritis 3 remains unclear. The working hypothesis most in agreement with known clinical facts is that the disease arises as a result of an allergic reaction 8 involving the walls of capillaries and the smooth musculature of the arterioles, both in and outside 을 the kidneys. In the latter organ these alterations $>$ tend to block glomerular circulation and produce an inflammatory exudation into Bowman's capsule, $\bar{N}$ with a resulting fall in glomerular filtration, $\odot$ oliguria (rarely anuria), proteinuria and excretion $N$ of erythrocytes, leucocytes and erythrocytic and $\mathcal{N}^{N}$ granular casts into the urine. The initial decrease in concentrating ability has already been men-co tioned. Extrarenally, spasm of the smooth $\stackrel{\leftarrow}{\overparen{D}}$ muscle of the arteriolar wall leads to a rise in $\stackrel{?}{?}$ blood pressure, increased capillary permeability $\underset{T}{T}$ and a shift of fluid into the interstitial space, $\frac{O}{\vec{P}}$ and the resulting mobilisation of the 'dehydration $\stackrel{\mathbb{Q}}{\mathcal{D}}$ reaction' leading to salt retention and œdema $\stackrel{\mathbb{Q}}{\stackrel{1}{\circ}}$ 


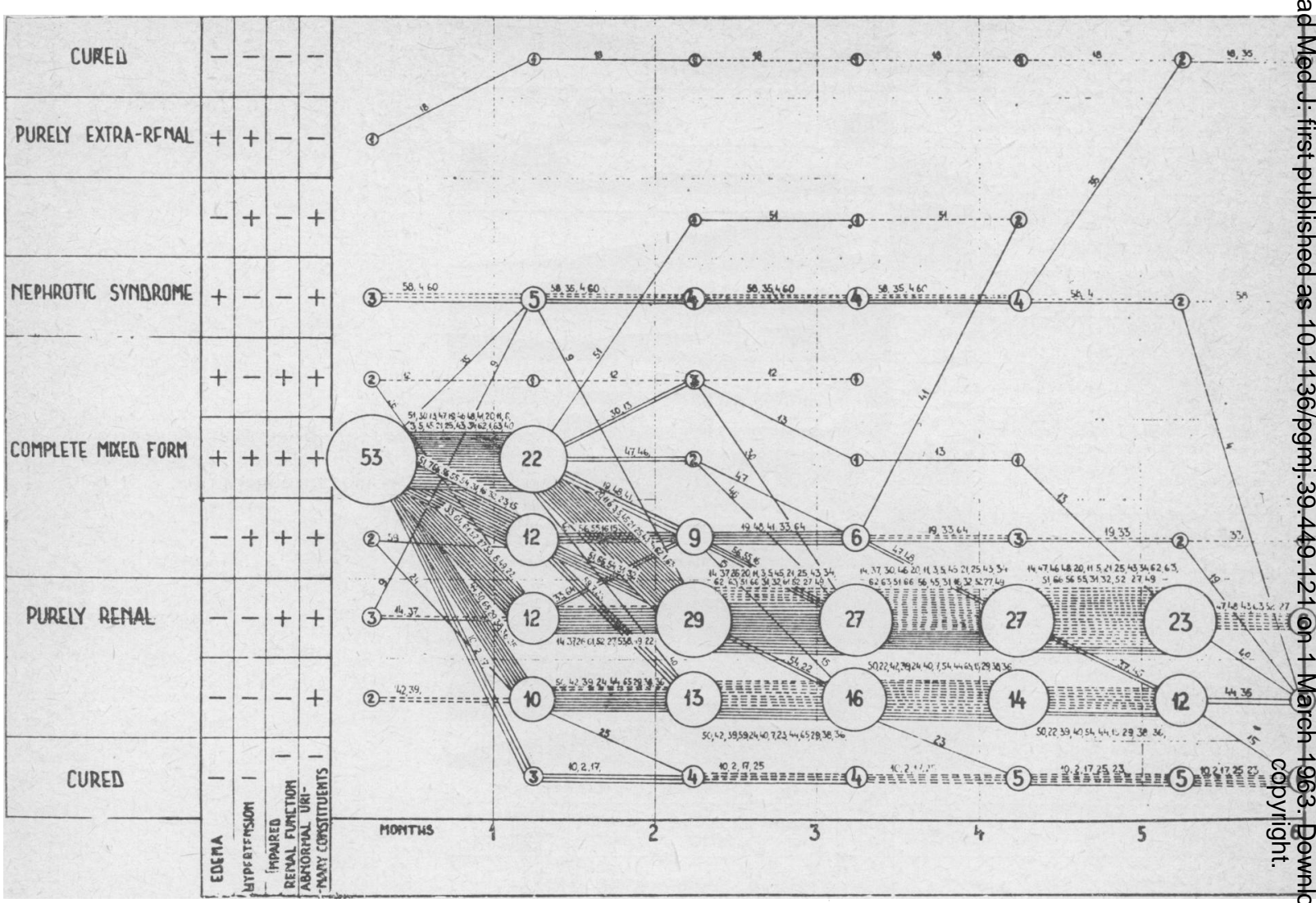

FIG. I1.-Grouping of leading signs and their development in a group of 66 patients with acute glomerulonephritis in the course of the first six months. The whole group has been split into subgroups according to the presence $(+)$ or absence $(-)$ of the individual signs, indicated on the left side of the graph. The figures in circles indicate the number of patients in each subgroup. Note that at the start over $80 \%$ of the patients exhibited all the four leading signs (hypertension, œdema, reduced GFR and changes in the urine). After one month these were still present in only one-third of the patients and after two months they subsided in all but two patients. However, only a small fraction of the patients moved into the subgroup 'healed'; in the majority signs of renal involvement persisted. After the acute phase there follows obviously a phase in which residual changes are present in the kidneys. The patient may be quite symptom-free at this stage of the disease.

formation. This assumed independent course of vascular changes in the kidneys and outside of them is supported by data from a series of 66 patients treated during the war in British Military Hospitals in North Africa and Italy (Fig. I I) (Brod, I949). As can be seen, some patients with acute glomerulonephritis had combined renal and extrarenal manifestations, while others showed only renal damage with or without glomerular blockade. There was a continuous gradation between these two groups, suggesting that they all had the same disease. At the other end of the scale the signs of the renal lesion were pushed into the background, leaving at the end only hypertension and œdema. Like the previous figure also, the present one demonstrates that the full-blown picture of the acute disease tends to subside within one to two months in the great majority of patients. The signs of obstruction of the glomerular circulation decreased, glomerular filtration rose again to normal values and hypertension and œedema receded, though not all necessarily at the same rate, which again lends support to the idea that the changes are independent expressions of the disease-process. However, signs of a lesion of the glomerular membrane, such as proteinuria, microscopic hæmaturia, and erythrocytic casts and leucocytes in the urinary sediment remained in some cases, along with signs of a decreased area for glomerular filtration-a decrease in the diurnal variation in glomerular filtration.

The further course of the disease can show three types of development. The signs of the disease can decrease over the following weeks or months, 


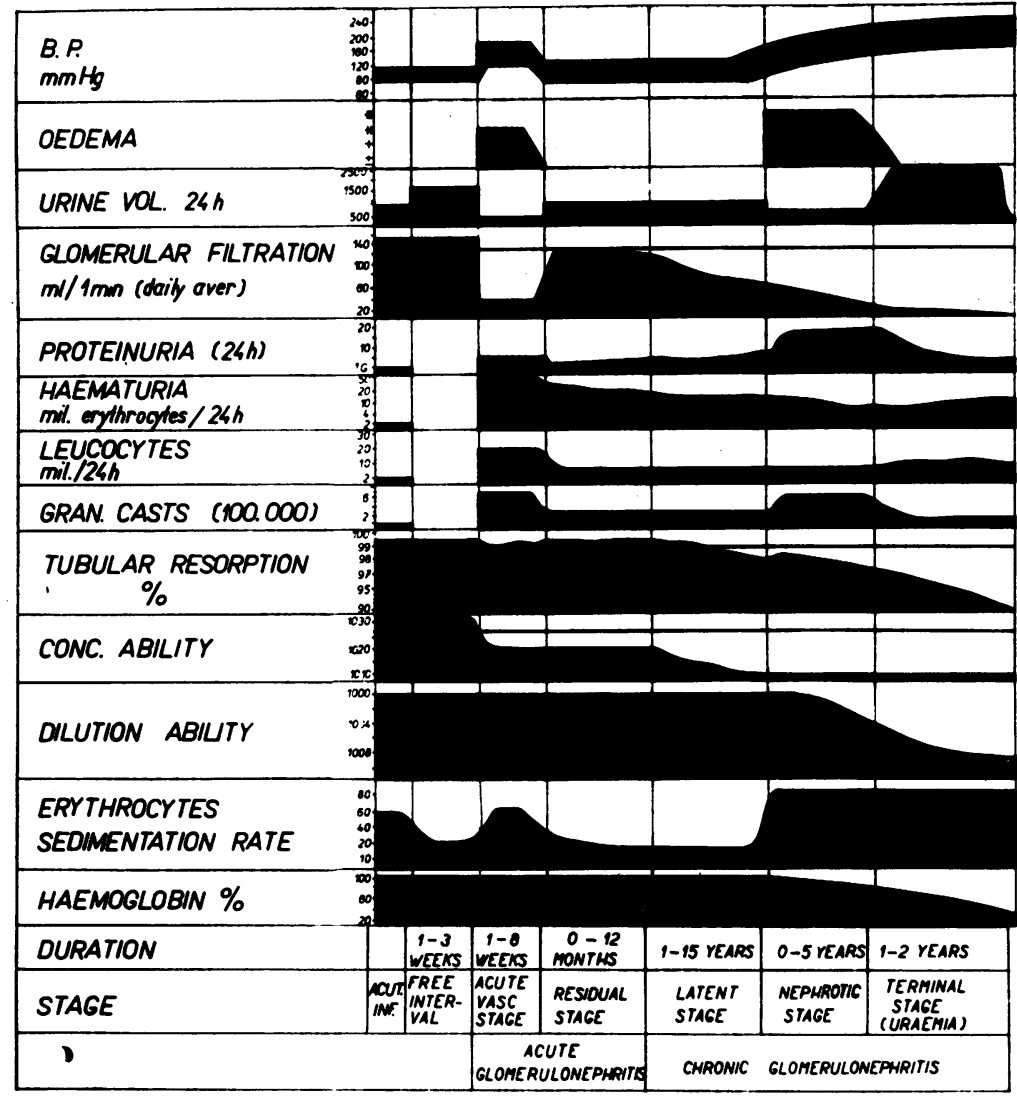

FIG. 12.-Diagrammatic representa6 tion of the development of $\bar{B}$. glomerulonephritis.

or the patient remains unchanged for years, or glomerular filtration can progressively decrease at a greater or lesser rate, either continuously, or in jumps, this being possibly related to intercurrent infection (Fig. 12).

The nephrotic syndrome or hypertension can complicate the further course of the disease, be it otherwise stationary or progressive. Hypertension occurs mainly in patients with disease of longer duration, and where glomerular filtration has decreased to below 50 to $60 \mathrm{ml} . / \mathrm{min}$. (Fig. 13). This hypertension may take on a malignant character and be the predominant clinical sign, while the functional state of the kidney remains as before, that is with red cells predominating in the Addis count, with marked proteinuria, casts in the urine, and a more or less parallel decrease in the rate of glomerular filtration and concentrating ability.

Recognition of the fully developed picture of acute glomerulonephritis is not difficult (Table 6). As opposed to œdema from right-sided congestive failure the venous pressure is normal and the rate of glomerular filtration does not increase at night; the decreased concentrating ability is in contrase $\overrightarrow{\overrightarrow{\vec{P}}}$ with the highly concentrated urine of the cardiacpatient, while with the exception of cases with renal infarction, hæmaturia in congestive failure is insignificant. Acute tubular insufficiency is usually preceded by shock or intoxication, and neithero hypertension nor œdema belong to the initial signs. If a small sample of urine can be collected in acutê tubular insufficiency, the presence of red cells is without diagnostic significance, but their absenceo rules out glomerulonephritis, just as in the case of a urine specific gravity below I.or2. With simple febrile proteinuria the rate of glomerular filtration is normal (provided that the basic disease has noe resulted in dehydration or myocardial damage) $N$ the concentrating ability is normal and the urinary N sediment may contain only an increased amounto of hyaline casts.

Malignant hypertension which occurs in chronic cases of severe essential hypertension might also be accompanied by a marked increase in proteinuriat and the number of elements in the urine, and oneo finds left ventricular hypertrophy, which is not present early in acute glomerulonephritis. There 
CHRONIC NEPHRITIS

CHRONIC PYELONEPHRITIS

GLOMERULO NEPHRITIS + PYELONEPHRITIS GLOMERULO-

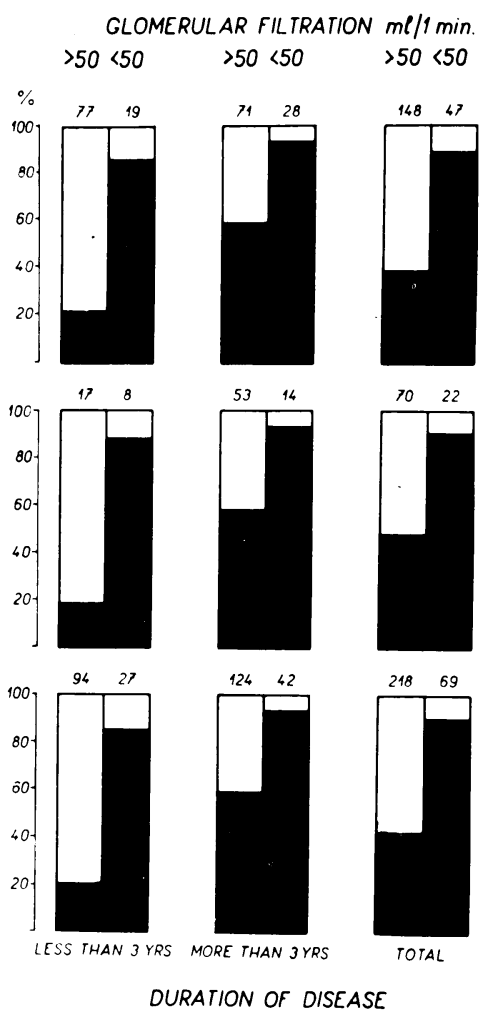

Fis. 13.-Incidence of hypertension (B.P. Over $1+595$ $\mathrm{mm}$. $\mathrm{Hg}$ ) in patients with chronic glomerulonephritis and chronic pyelonephritis in relation to the grade of reduction of GFR and to the duration of the discase.

is also a high filtration fraction* (if known), while the frequent absence of erythrocytes or casts in the urine also tends to exclude glomerulonephritis.

*Ratio of the rate of glomerular filtration renal plasma flow (PAH clearance).
Differential diagnosis may be difficult in the latent stage of chronic glomerulonephritis with only residual changes in the urine, particularly if there is no history of an acute initial disease (Table 7). As opposed to benign forms of proteinuria, protein is present in the morning urine, the Addis count is high and there are functional signs of renal impairment. A history of odema and oliguria is evidence against chronic pyelonephritis, whereas a history of back pain, nephrolithiasis or some other urological disease such as repeated cystitis speak in favour of the latter diagnosis. Proteinuria greater than 5 g. 24 hr., a large number of casts in the sediment (over 1 to 2 million in $24 \mathrm{hr}$.) as well as a marked increase in both red and white cells in the sediment are all evidence for glomerulonephritis, rather than pyelonephritis, in addition to a concentrating ability which is decreased in proportion to the degree of decrease in the rate of glomerular filtration. Symmetrical renal involvement, as determined by separate collection of urine from each ureter, is not characteristic of pyelonephritis. $\mathrm{X}$-ray investigation of the urinary passages can also be used to test for symmetry, and a normal picture here is not the rule in pyelonephritis. We can exclude primary vascular nephrosclerosis accompanying hypertensive disease by the fact that in a disease of a short duration and without grave kidney involvement there is often no rise in blood pressure (Fig. 13). Nephrosclerosis is not accompanied by marked proteinuria or a high Addis count, the concentrating ability is only moderately affected and usually far less than one might expect from the degree of depression of glomerular filtration. 'The filtration fraction is raised in nephrosclerosis, but decreased in glomerulonephritis. Of the other disease-states associated with the nephrotic syndrome, amyloid can be excluded on the basis of the history, the lack of red cells in the urinary sediment, a satis-

TABLE: 6

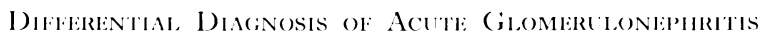

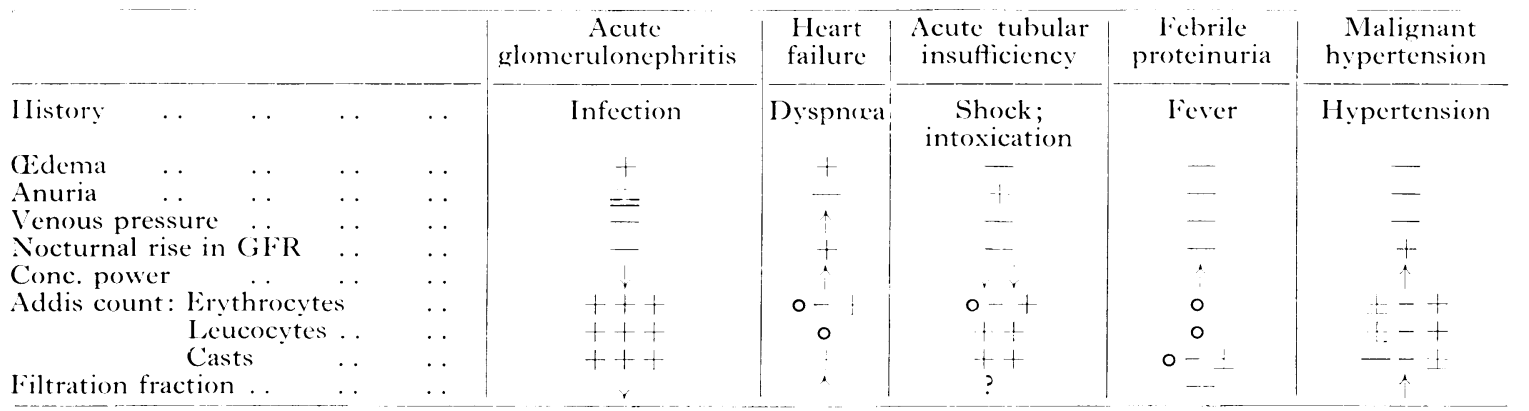


TABLE 7

Differential Diagnosis of Chronic Glomerulonephritis

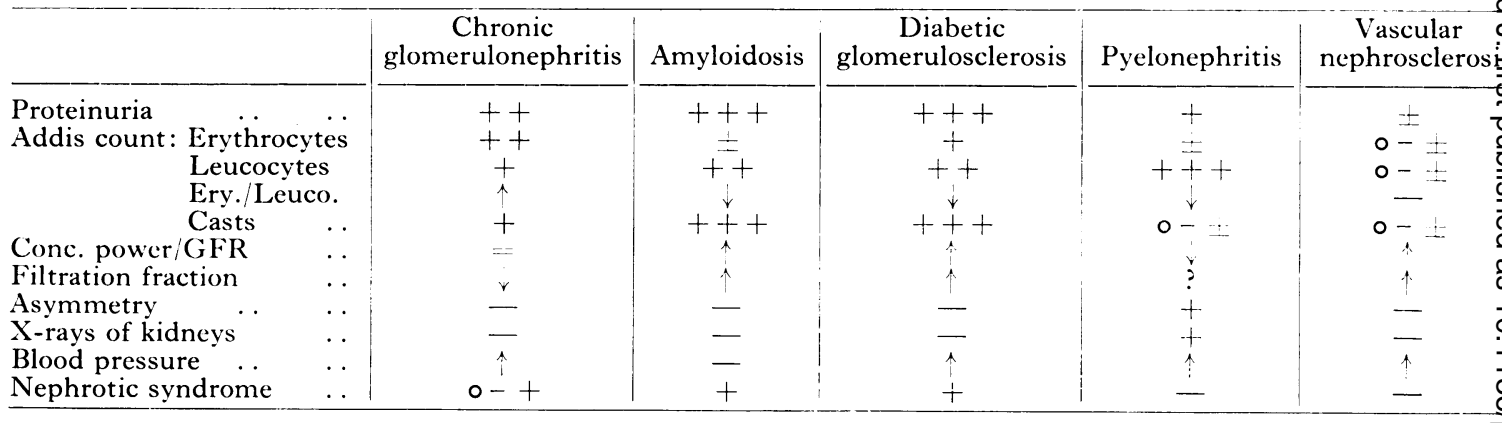

factory concentrating ability and absence of hypertension provided that the patient is not in renal failure. The first three of these criteria also exclude diabetic glomerulosclerosis, quite apart from the fact that for the latter diagnosis we must also observe diabetes and retinopathy.

Differentiation between glomerulonephritis and nephropathia gravidarum has already been discussed. The very difficult differentiation from renal venous thrombosis may be assisted by a history of thrombosis of the lower extremities, the presence of visible collateral vascular channels on the abdominal wall, and the combination of a satisfactory concentrating ability with only slight hæmaturia.

These differential diagnostic criteria remain valid even in the presence of renal failure. Fig. I4 shows that even at this stage these criteria are not merely of academic interest, since using them we can determine the prognosis, which is very different in glomerulonephritis as compared with pyelonephritis (Prát, Fencl and Jirka, I96r).

\section{Renal Diseases, Affecting Primarily Tubular Function}

Group 3 contains those renal diseases which affect primarily tubular function, and which is represented by chronic pyelonephritis and polycystic disease. The correctness of this classification in the case of pyelonephritis can be seen already by observing a histological section (Fig. I5), where it can be observed that the normal contour of the tubule is lost in an interstitial inflammatory infiltrate, spreading irregularly through the kidney, whereas glomeruli are involved, in the form of a glomerulitis, only very late in the course of the disease. Lambert (1943) has established the primary involvement of the tubules in polycystic disease by means of a plastic reconstruction which revealed that the cysts originated from the tubular lumen. In addition, these inadequate

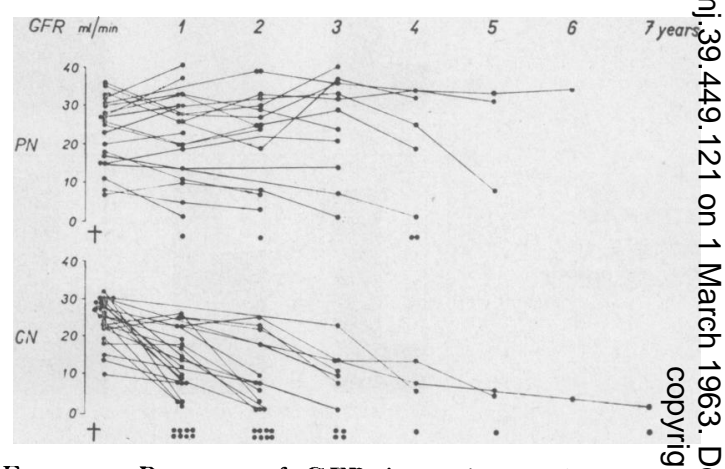

FIG. I 4.-Progress of GFR in patients with chroflic pyelonephritis (PN) and chronic glomerulo nephritis $(\mathrm{GN})$ who were first seen with a GFF reduced below $35 \mathrm{ml} . / \mathrm{min}$. Note that the rate of descent of GFR is faster in patients with glomerulo $\Phi$ nephritis than pyelonephritis and that in the course of seven years all the patients with glomeruloo nephritis were dead, while $80 \%$ of the pyelo 3 nephritics survived. The ages of both group were comparable (Prát, Fencl and Jirka, I96I).

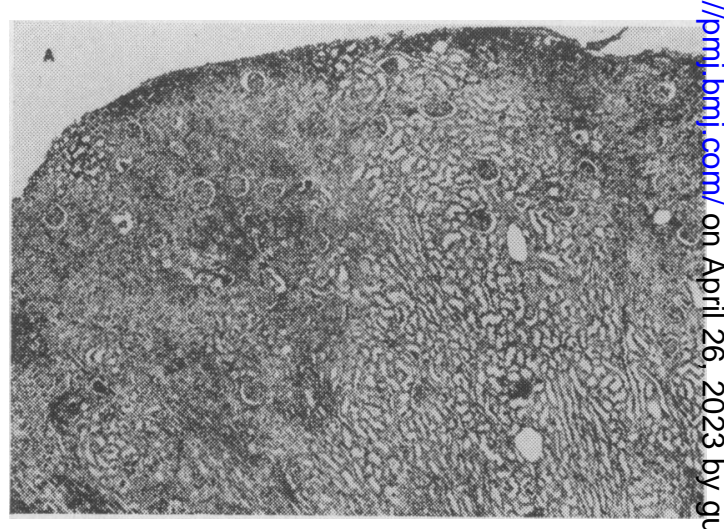

FIG. 15.-Microscopical picture of chronic pyelo nephritis. Note the heavy round-cellular infiltra? tion of the left half of the kidney and the normato appearance of the right half. In the inflameab zone the outlines of the tubules have practically disappeared, while the structure of glomeruli is well preserved. 


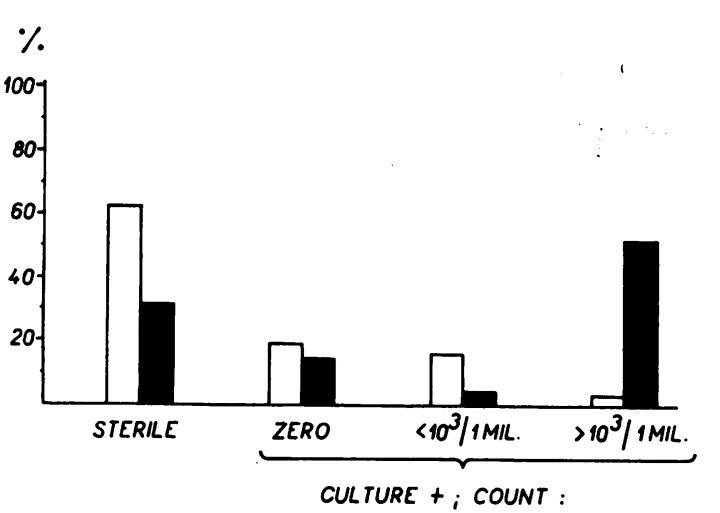

GLOMERUL ONEPHRITIS

\section{PYELONEPHRITIS}

FIG. 16.-Quantitative bacteriology of the urine in chronic glomerulonephritis and chronic pyelonephritis. Note the high incidence of severely infected urines in chronic pyelonephritis (Prát and Horák, in press).

organs are also very susceptible to infection and chronic pyelonephritis.

Chronic pyelonephritis arises on the basis of an interstitial infection and in $60 \%$ of cases the causative agent can be isolated from the urine in quantities which exclude the possibility of chance contamination of the samples, i.e. usually more than 10,000 and as a rule up to 100,000 organisms/ ml. (Fig. I6). With late involvement of the glomeruli proteinuria need not be, but usually is, present, but seldom reaches values greater than I to $2 \mathrm{~g} . / 24 \mathrm{hr}$. (Fig. I7). It is perhaps a consequence of an abnormal circulation in the glomeruli due to pressure from the inflammatory exudate. In favour of this is the fact that treatment of the infection at this stage may result in a rise in glomerular filtration. In addition to protein and micro-organisms in the urine we can also find there a direct reflection of the interstitial inflammation in the form of leucocytes, which are more numerous in the Addis count than red cells in $75 \%$ of cases (Fig. 2). Casts, so typical in histological section, arising in nephrons which have been blocked by the inflammatory process, are few or absent.

There is a characteristic decrease in concentrating ability present from the early stages of the disease, in sharp contrast to the lack of involvement of glomerular filtration, as can be seen in Fig. 3. As opposed to glomerulonephritis and vascular nephrosclerosis, there is a decrease in the specific gravity of the urine in the final stages of the disease to values below those of the glomerular

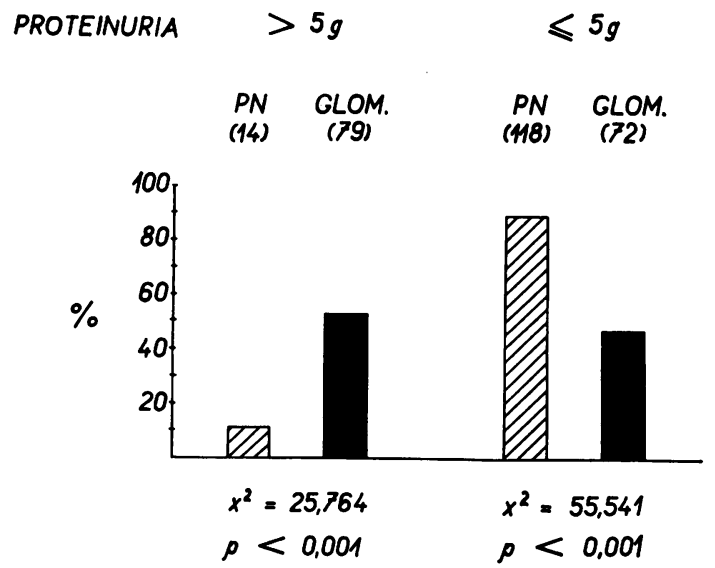

FIG. 17.- Severity of proteinuria in chronic pyelonephritis (PN) and chronic glomerulonephritis (GLOM).

filtrate. This tubular involvement from the early stages of the disease is one of the causes of the continuing tendency to extracellular dehydration in these patients, which acts in the opposite direction from the tendency to œdema formation in congestive failure. Since protein-loss is smallo and since there is a tendency to lose salt rather than retain it, the nephrotic syndrome is never seen in? chronic pyelonephritis.

The irregularity of the spread of the disease process in the kidney explains the asymmetry of the two kidneys found in $90 \%$ of cases by analysis of creatinine concentration separately in the urine collected by catheter from each ureter (Prát and Kočvara, 1957) (Fig. 18), as well as by X-ray studies of the size and shape of the kidneys and the rate at which injected contrast material appears in the renal pelvis (Dejdar, 1959). The latter technique has also demonstrated abnormal shapes of the calyces, papilla and pelvis, and abnormal motility of the ureter in serial films (Figs. 19 and 20).

There are, therefore, a large number of signs which assist in the diagnosis of this most frequent of renal diseases, provided that we consider this diagnosis not only in clear urological cases, but also in all cases of asymptomatic proteinuria, hypertension with proteinuria and even in patients with vague, general complaints, e.g. minimal temperatures. Urinary examination will then give rise to the initial suspicion of pyelonephritis, and the above detailed tests can establish the presence of the disease (Table 8).

The presence of the nephrotic syndrome excludes the diagnosis of chronic pyelonephritis. Even without odema, the presence of heavy 


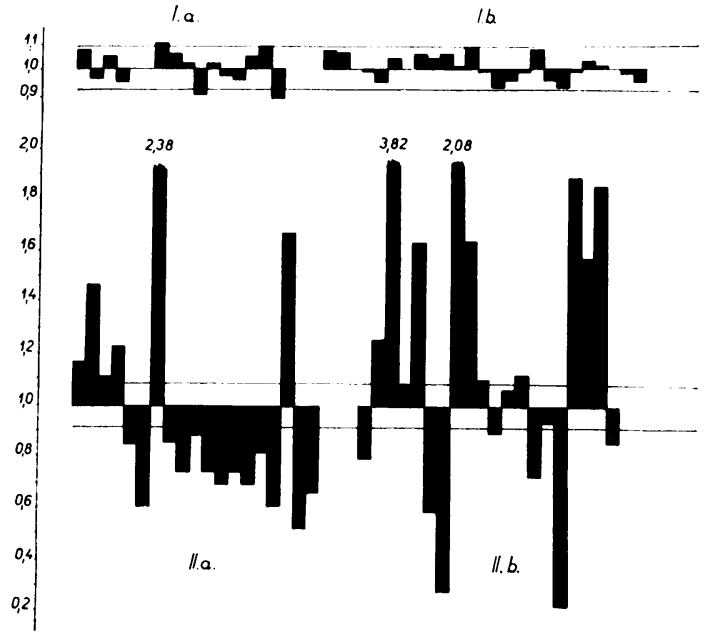

Fig. 18. - Ratio of the concentration indices of endo genous creatinine of the left and right kidney in? subjects with normal kidneys (left upper group)? in patients with chronic glomerulonephritis and vascular nephrosclerosis (right upper group) and in patients with chronic pyelonephritis. The thire lines indicate the $\pm 10 \%$ limit, within which are situated almost all the data of subjects with norma? kidneys and with the symmetrical bilateral diseases In the right subgroup of pyelonephritis a unilateraP disease was suspected on other grounds, whereas no such suspicion existed in cases in the left subs group (Prát and Kočvara, 1957).

FIG, 19.-X-ray picture of chronic pyelonephritis. Note the unequal size of the two kidneys, the blunting of th $\vec{\Phi}$ calyces, the flattening of the papilla and the uneven thickness of the parenchyma overlying the renal pelvif (Dejdar, I959). 

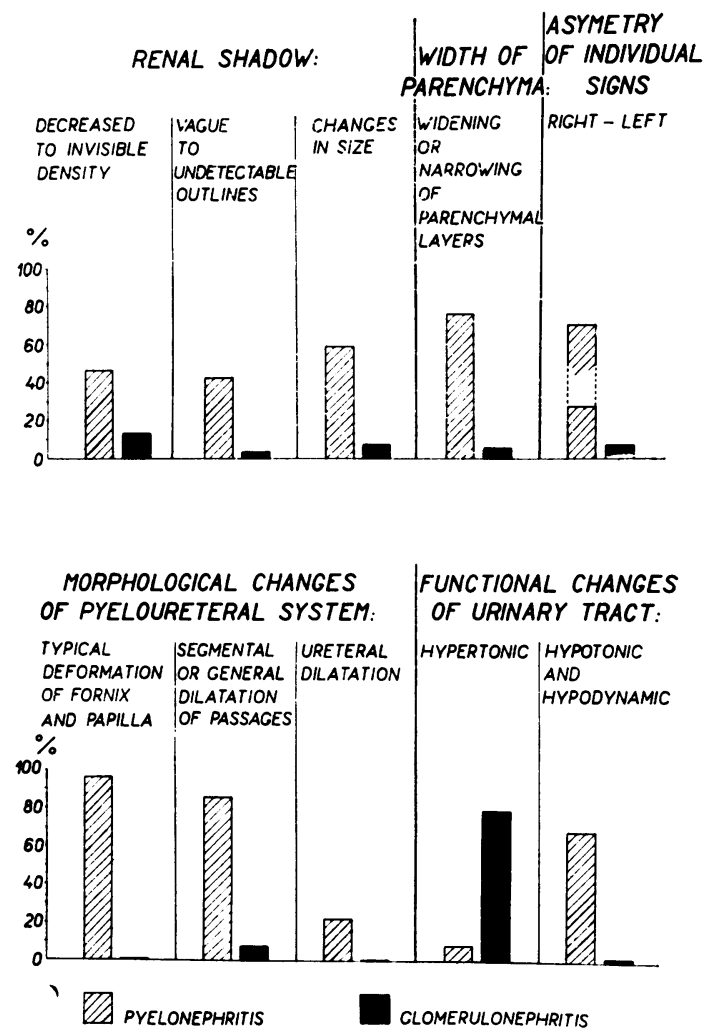

FIG. 20.-Summary of the $\mathrm{X}$-ray findings in chronic pyelonephritis. Patients with chronic glomerulonephritis were used for comparison (Dejdar, 1959).

proteinuria and casts in the urinary sediment rather indicate glomerulonephritis, diabetic glomerulosclerosis, amyloidosis or nephropathia gravidarum. The last-named three syndromes in addition show a higher concentrating ability than

TABle 8

Differential Diagnosis of Chronic Pyelonephritis and Polycystic Kidney Disease

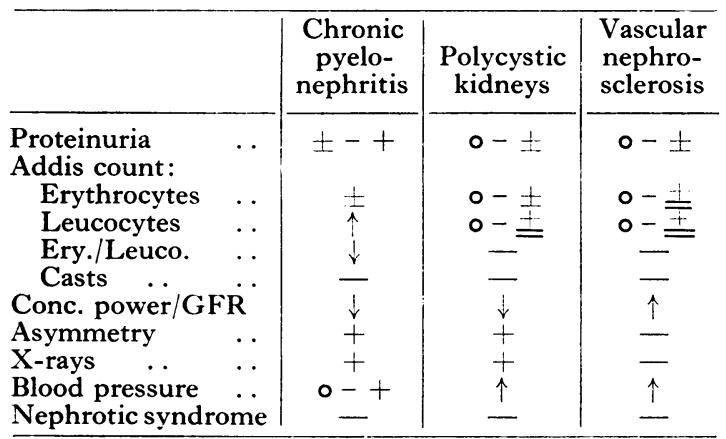

corresponds to the decrease in the rate of glomerular filtration. Primary vascular nephrosclerosis is an after-effect of hypertension, and can thus be excluded in $40 \%$ of cases of pyelonephritis who run the course of their disease with normal pressures. In the presence of hypertension, the pyelonephritic case will show a predominance of leucocytes in the urinary sediment, bacteriuria, a greater restriction of concentrating ability in relation to the level of glomerular filtration, asymmetry and pathological X-ray findings.

Polycystic disease shows a similar accentuation of loss of concentrating ability in relation to glomerular filtration as in pyelonephritis, but the urine is not infected and does not contain leucocytes if the polycystic organ has not become secondarily infected (Table 8). The most important differential diagnostic criteria are the findings on palpation and X-ray.

Table 9 summarizes the differential diagnostic criteria of the individual disease states, as presented above. The validity of these criteria is documented in Fig. 2I, which shows the high degree of correlation between the functional diagnosis and the histological findings. Moreover, the functional diagnosis is at the same time a quantitative one, and gives more information than can be obtained from a small biopsy sample.

\section{Conclusion}

Modern renal physiology-from its very beginnings in London with Bowman and Cushny-has put clinical nephrology on a scientific basis which was lacking when Bright first set his observations down on paper. It is to be hoped that it will continue to provide more effective measures to control and eradicate kidney disease, with which until recently the physician was forced to play more the role of the observer than of the therapeutist.

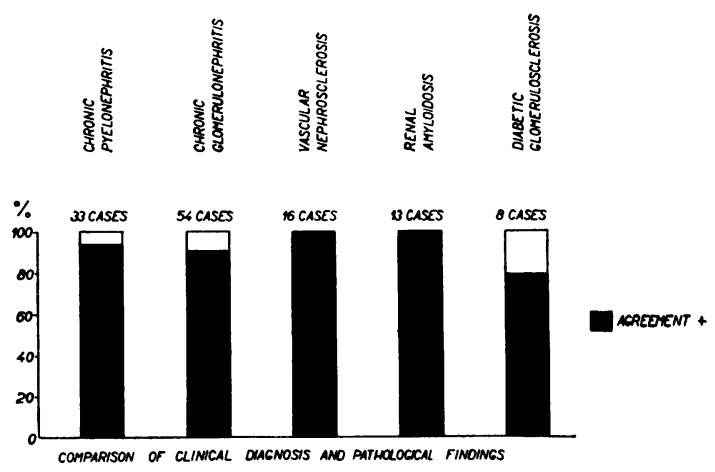

FIG. 21.-Degree of agreement between the clinical and morphological diagnosis of the most important renal diseases. 


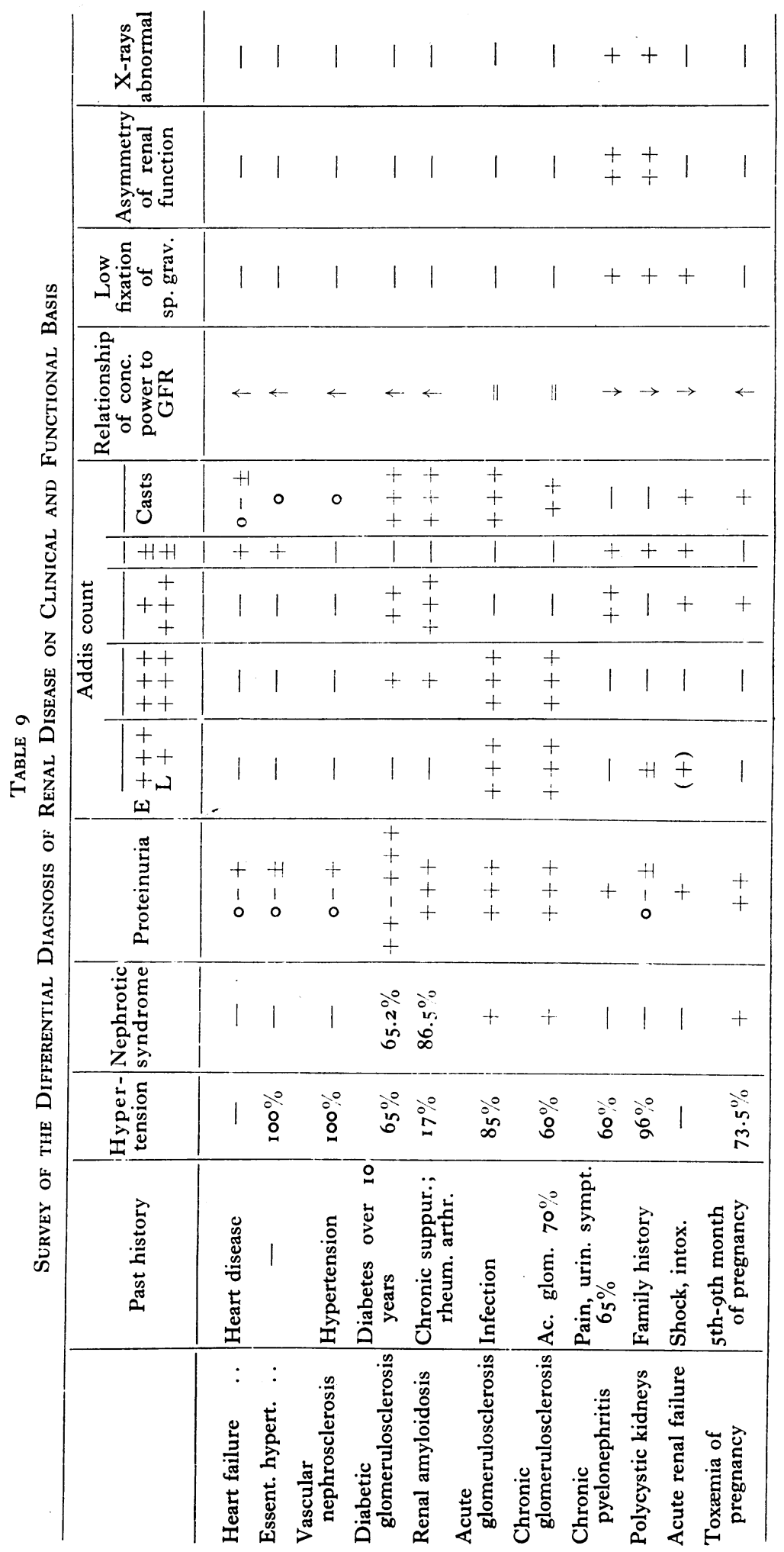




\section{REFERENCES}

Addis, T. (1942): Proteinuria, Trans. Ass. Amer. Phys., 57, 106.

Antoine, B. (196I): Personal communication.

Bradley, S. E., Chasis, H., Goldring, W., and Smith, H. W. (1945): Hæmodynamic Alterations in Normotensive and Hypertensive Subjects During the Pyrogenic Reaction, 7 . clin. Invest., 24, 749. ·

Bright, W. (I 827): ' Reports of Medical Cases Selected with a View of Illustrating the Symptoms and Cure of Diseases by a Reference to Morbid Anatomy'. London: Longman, Rees, Orme, Brown and Green.

- (1836): Cases and Observations Illustative of Renal Disease Accompanied with the Secretion of Albuminous Urine, Guy's Hosp. Rep., r, $33^{8}$.

Brod, J. (1949): Acute Diffuse Glomerulonephritis, Amer. F. Med., 7, 317.

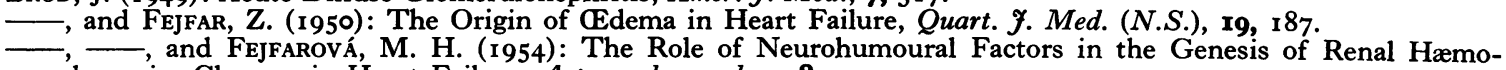
dynamics Changes in Heart Failure, Acta med. scand., 148, 273.

, and FENCL, V. (I955): Ledvinová hemodynamika a funkce v průběhu léčby hypertensní choroby výtažkem $z$ Rauwolfia serpentina Rivadescinem (Renal Hæmodynamic and Function in the Course of Therapy of Essential Hypertension with an Extract of Rauwolfia Serpentina Rivadescin), Vnitřni Lék., r, 539.

hypertoniků (Mechanism of General and Renal Hæmodynamic Changes During Day and Night. II. Behaviour of Hypertensives), Cas. Lék. čes., 97, 1025.

,-- HEJL, Z., and JiRKA, J. (1959): Circulatory Changes Underlying Blood Pressure Elevation During Acute Emotional Stress (Mental Arithmetic in Normotensive and Hypertensive Subjects), Clin. Sci., 18, 269.

Brun, C., Gormsen, H., Hilden, T., Iversen, P., and RaAschou, F. (1953): Diabetic Nephropathy, Amer. F. Med., I5, 187.

DEJDAR, R. (1959): Die chronische Pyelonephritis in roentgenographischer Darstellung. Eine zusammenfassende Studie zur Diagnostik morphologischer und funktioneller Veränderungen pyelonephritiskranker Nieren, Fortschr. Röntgenstr., 90, 198.

Goverts, P., and Lambert, P. P. (1953): Physiopathologie de la protéinurie, Y. Urol. méd. chir., 59, 693.

Hejl, Z., PRÁt, V., and DEJDAR, R. (1962): Význam aortografie pro klinickou diagnostiku hypertense (Significance of Aortography for the Clinical Diagnosis of Hypertension), Czechosl. Cardiol. Soc., Prague, April 4.

Horn, R. C., and Smetana, H. (1942): Intercapillary Glomerulosclerosis, Amer. F. Path., 18, 93.

IVERSEN, P., and OHLSEN, A. S. (I95I): Intercapillary Glomerulosclerosis, Acta med. scand., I39, 319.

LAIPPly, T. C., EITZEN, O., and DutRA, F. R. (I944): Intercapillary Glomerulosclerosis, Arch. intern. Med., 74, 354.

LAMBERT, P. P. (1943): 'Le rein polykystique.' Paris: Masson.

Prát, V., and Kočvara, S. (1957): Oddělené funkční vyšetření ledvin: Metodika a klinické použití ' ( Separate Examination of Renal Function: Method and Clinical Use'). Praha: St. zdrav. nakl.

- FENCL, V., and JiRkA, J. (I96r): Průběh chronické renální insuficience u nemocných chronickou pyelonefritidou a u nemocných chronickou glomerulonefritidou (The Course of Chronic Renal Failure in Patients with Chronic Pyelonephritis and Chronic Glomerulonephritis), Czechosl. Urol. Soc., Smolenice, October 25.

- and HoRÁk, O. (1962): Porovnání bakteriologických nálezů u chronické pyelonefridity a u chronické glomerulonefritidy (Comparison of Bacteriological Findings in Chronic Pyelonephritis and in Chronic Glomerulonephritis),
Vnitřni. Lék. in press.

RatNĚr, N. N. (1959): Znachenie issledovanii funktsii pochek dlia differentsiaĺnoi diagnostiki khronicheskogo pielonefrita, khronicheskogo glomerulonefrita $\mathrm{i}$ gipertonicheskoi bolezni, X nauchnaia sessiya Instituta terapii AMN SSSR 14, March 16.

SchwentKer, F. F., and Comploier, F. C. (1939): The Production of Kidney Antibodies by Injection of Homologous Kidney Plus Bacterial Toxins, $\boldsymbol{F} . \exp$. Med., 70, 223.

Shannon, J. A. (r942): The Control of the Renal Excretion of Water. I. The Effect of Variations in the State of Hydration on Water Excretion in Dogs with Diabetes Insipidus, $\mathfrak{f}$. exp. Med., 76, 371.

DE WARDENER, H. E., and DEL GRECO, F. (1 955): The influence of Solute Excretion Rate on the Production of a Hypotonic Urine in Man. Clin. Sci., $14,715$.

- Solute Output during a 'Water Diuresis'. F. Physiol., r3r, 307. 